REVISTA CHILENA DE LITERATURA

Noviembre 2009, Número 75, 157 - 170

\title{
EL ACTO DE NOMBRARSE MISTRAL EN POEMA DE CHILE
}

\author{
Magda Sepúlveda Eriz* \\ Pontificia Universidad Católica de Chile \\ msepulvu@uc.cl
}

\section{RESUMEN / ABSTRACT}

La viajera espectral de Poema de Chile reflexiona sobre la adopción del nombre Mistral. Los fundamentos de esta elección van desde retornar a una intimidad anterior, la escena primigenia del campo, hasta el rechazo a la sociedad urbana. Este acto moderno de autonominarse constituye una atribución consciente frente al menoscabo y a los insultos recibidos en una posición representativa anterior. En vista de lo cual, la fantasma reclama los lugares, las palabras, los bienes y exige la recomposición de los cuerpos despedazados por el discurso blanco y etnocéntrico.

Palabras Clave: Mistral, poesía chilena, nombre, ciudad.

The travelling spectrum of Poema de Chile reflects on the adoption of the name Mistral. The causes of this choice go from coming back to a previous intimacy-the original scene of the country - to the rejection of the urban society. The name she gives herself is a conscious act and therefore, a modern one, which is used as a response to the damage she received when she was in a previous situation. As a result, the ghost calls for the places, the language and the goods that were stolen, and she demands to recover the bodies that were torn by the white and ethnocentric discourse.

KEY WORDS: Mistral, Chilean poetry, name, city.

* Este texto se vincula al proyecto Fondecyt 1085255, "Representaciones de la ciudad en la poesía chilena posgolpe", del cual quien suscribe es la investigadora responsable. 
Comenzaré por dos escenas artísticas que elaboran la importancia de los apellidos, como indicadores de clase, en Chile. Primero, un texto del joven escritor Pablo Paredes (1982), cuyo poema "Cuidado con el perro quiltro" corresponde a una declaración de amor atravesada por la clase: "Me gustaba que se llamase Yasna, me gustan los nombres que avisan la pobreza, esos nombres como Jhonatan y Jennifer, esos nombres que dicen cuidado con el perro quiltro, que marcan terreno, que avisan la selva. La clase media hace chiste con esos nombres, les parecen ridículos y graciosos sobre todo cuando son deformaciones anglo que se mezclan con un pobre Pérez (...). La clase media se ríe en función de los nombres connotadores de pobreza, ahí intentan marcar sus diferencias, sus privilegios, su idílico origen común, pero la clase media omite los apellidos, ellos también son Martínez y Hernández, aunque antecedidos por Camilos, Ignacios y Franciscas. No se meten con los apellidos, porque desde allí son desplazados. Se llamaba Yasna Rivas y la amé tanto" (Paredes 13). Tres sectores sociales son reconocibles por sus nombres en el poema de Pablo Paredes y cada estrato se burla de su vecino más desposeído. La segunda escena corresponde a la película Diálogo de exiliados (1974) de Raúl Ruiz; recojo específicamente la secuencia del personaje del exiliado chileno de sector acomodado quien le habla a la cámara para calificar el golpe militar como una acción de mal gusto, propia de los sectores de clase media nacionales: "Se ha metido en el camino esta gente de mediopelo, estos carabineritos, estos Pinochet, esta gente que no sabe ejercer el poder". Por el contrario, él se reconoce en otra clase, apta para gobernar, condición que justifica a través de sus apellidos: "Fernando Vial Errázuriz, Vial por parte de padre, sobrino nieto de Balmaceda y Errázuriz por parte de madre". Esta preocupación por el nombre atraviesa estos textos artísticos de diversas épocas, dando cuenta con ello de una carencia nacional. Chile es un país sin nombre ${ }^{1}$, de sujetos heridos por "el hueco simbólico del pater" (Montecino, Madres 33), por eso buscador de genealogías inexistentes, y

1 En el ensayo Chile o una loca geografia de Benjamín Subercaseux, que Gabriela Mistral prologó, el autor dice "Chile no tenía nombre. (F)ue, en el periodo de las invasiones parciales cuando se habló de la Tierra de Chili. ¿Era un ave -como algunos creen- la que articulaba esas dos sílabas en su canto?¿Era una planta la que se llamaba así, o alguna costumbre de los pobladores (...)?, ¿se trataba de algún apodo burlesco? (...) No sabemos (...). Por fin, la palabra Chilli, en lengua aymará quiere decir 'donde se acaba la tierra'" (58). Me parece que el problema del origen del nombre se extiende sobre sus habitantes, bajo la modalidad de destacar la genealogía de los apellidos. 
acostumbrado a usar la pregunta por el origen: 'esta niñita, ¿de quién es hija?' Gabriela Mistral asume en Poema de Chile $(1967)^{2}$ de forma rebelde esta pregunta. La respuesta lírica que fabrica la poeta es: del viento. Mistral corresponde al nombre de un viento frío que atraviesa parte de España e Italia. Este apellido también proviene del poeta Federico Mistral, pero en este ensayo seguiré solo las simbolizaciones por las cuales la hablante concibe su nominación en el poemario citado, a saber solo lo liga al viento. La creación de este apellido en el poemario opera como una sutura de otra(s) tachadura(s), esas que le decían 'ninguna', 'aparecida', 'pagana', poco femenina, cada una de las cuales Mistral recuerda y va respondiendo en Poema de Chile. El libro es legible entonces como un atlas de recomposición hacia un sí misma

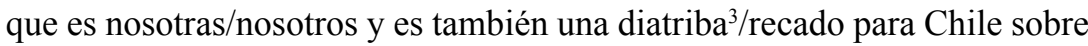
nuestro nombre.

La elección del viento Mistral como patronímico es explicada por la voz a su acompañante en Poema de Chile de esta manera: “- ¿Quieres decir, mama, que / a ese loco le obedeces? / - Tal vez, chiquito. Me gusta / caminar con él, seguirlo, / hablarle a trechos, decirle / viejas palabras mimosas. / Él tiene cuarenta nombres / y uno le robé, sin miedo" (153). En la cita, el nuevo nombre se relaciona con el viento y con el lenguaje. Ahora recordemos que el soplo de aire tiene un poder creador, por lo tanto, el nuevo nombre la acerca a su rol en la cultura, ser poeta. Su denominación no es dada por otros, sino que ella se nombra a sí misma. Thiebaut distingue dos maneras de nombrar, el procedimiento antiguo y la forma moderna. En la manera arcaica, el sujeto recibe su nombre y su función; Thiebaut plantea, como paradigma, el caso de Jacob quien obtiene de Dios el nombre de 'Israel' y su identidad de luchador ${ }^{4}$. El mismo ejercicio se presenta en tribus ancestrales, donde un

2 De acuerdo con las investigaciones de Ana Pizarro, Poema de Chile, libro publicado póstumamente, se comienza a diseñar en los años 40 en Brasil en un diálogo con Romancero da Inconfidencia de Cecilia Meireles, publicado el año 1953, "donde también se elabora el imaginario nacional en tono romance" (Pizarro 62).

3 Diatriba era "en la antigüedad, disertación de carácter didáctico o moral. Muy pronto el término significó, sin embargo, discurso polémico o sarcástico" (Marchese 101). Bajo esta fórmula fue practicada por los filósofos cínicos, quienes veían en la civilización el origen del mal y se acercaban a la naturaleza como fuente de felicidad. Haciéndose eco de los cínicos, Mistral en Poema de Chile evita las ciudades y traza un recorrido por la ruralidad de Chile.

4 Jacob había recibido las bendiciones de la primogenitura, haciéndose pasar por su hermano Essaú, para ello utilizó un cabrito que simulaba la piel velluda de su hermano mayor. 
integrante recibe su nombre y su tarea, ya sea esta de hechicero, cazador $\mathrm{u}$ otra. Por el contrario, en el nombrar moderno no se recibe la identidad junto con el nombre, dado lo cual el sujeto debe buscar su función. En el nombrar moderno, el sujeto tiene conciencia del lenguaje y sabe que el nombre está precedido por un texto. En términos de Lacan: "los símbolos envuelven en efecto la vida del hombre con una red tan total, que reúnen antes de que él venga al mundo (el) dibujo de su destino, que dan las palabras, que lo harán fiel o renegado" (268). La reflexión sobre la red que nombra y el desafío al nombre es un hecho moderno cuya ocurrencia se presenta "cuando un nombrar no es ya la clave de un ser y este no se reconoce en aquel, es que ese alguien ha encontrado un nuevo lugar que se define en un sistema de acción diferente y un sistema de significación distinto" (Thiebaut 118). La voz de Poema de Chile participa de la conciencia moderna del nombrar, por ello entrega los antecedentes del rechazo al nombre que la precedía, justifica la designación que se otorga a sí misma y explica sus nuevas funciones.

La voz de Poema de Chile recorre el país sin patronímico heredado, el Godoy es borrado, aunque, en estricto rigor, ya tenía esa condición, pues pertenece a esos apellidos que nacen tachados. Tras el análisis de unos datos, el diario El Mercurio concluye: "Para un chileno cualquiera un apellido porta suficiente información como para hacer jerarquías solamente a partir de ese dato. Por algo Infante no es lo mismo que Machuca; (lo que explica) que un mal alumno de clase alta obtiene ingresos un 15 por ciento mayores que un buen alumno de origen popular" (El Mercurio E3). El Godoy de Mistral pertenece a los Machuca, vale decir, un apellido que condiciona un lugar marginal en la cultura chilena. Desde este punto de vista, gran parte de los chilenos(as) no tenemos nombre, por ende, la ficción del origen es nuestra historia - la peripecia, diría Aristóteles. Mistral regresa al país sin nombre en la condición de fantasma, indicándose con ello la situación de quien tiene algo que saldar, una deuda que me parece tiene que ver con la tachadura. Mistral reconoce en la condición de fantasma su lugar en la cultura chilena, el 'ninguneo' que examina con burla: “Ja, ja, ja. Yo soy un fantasma, /pero cuando era una viva, /nunca me tuve la suerte/de ser de rutas oída" (36). Mistral asume la condición fantasmal como ejemplificación del mote de 'aparecida' (109)

Luego, Jacob pelea con un ángel a quien gana y el cual, a cambio de dejarlo libre, le da el nombre de Israel: "No se dirá más tu nombre de Jacob, sino Israel porque has peleado con Dios y con los hombres y has vencido" (Génesis 32-28). 
que le recuerda el niño-ciervo-huemulillo que la acompaña. La calificación de 'aparecida' remite en Chile al individuo que no tiene méritos, que no hizo carrera, para estar en la posición que ocupa; tal adjetivo puede recaer en un sujeto de sectores medios o populares, pero no en un personaje aristocrático cuyo apellido lo valida, tenga o no méritos.

José Luis Romero plantea en Latinoamérica, las ciudades y las ideas que, desde los inicios coloniales, ciertas ciudades latinoamericanas han tenido el modelo de la corte como estructura de funcionamiento. En ellas, el habitante aceptaba ocupar un puesto en una "sociedad severamente jerarquizada que presidía un monarca o un gran señor, de la que recibía la seguridad del respeto a su dignidad y su decoro y, además la posibilidad de la merced, para cuya obtención no era denigrante el ruego sumiso. (...) El ámbito de esa sociedad era la corte, ceremoniosa, esclava de una etiqueta rígida, severa en las formas pero minada por el juego de las intrigas y los apetitos, agitada siempre por la esperanza de alcanzar el favor real o el temor de perderlo" (Romero 115). Cuando se le dice a Mistral 'aparecida', se la ubica dentro del sector que ocupan (mos) los sin patronímico y se le insinúa que no debe moverse de allí. Mistral toma este insulto que cae sobre ella y lo transforma acentuando su vertiente popular rural, 'el aparecio', el 'alma en pena'. El 'ninguneo' de la cultura nacional es transformado por Mistral en una práctica contra sí misma, ella se borra, se cambia de nombre y de país, por ello el recuerdo de su nombre abandonado lo experimenta como trauma: "Y tú, ¿tienes otro nombre/(...)-Sí, el que me dieron/y el que me di de mañosa/y el nuevo me mató el viejo./No averigües más. ¡Camina!” (41). De esta manera, el nombre de Mistral está elaborado sobre una escena anterior de la cual no es posible hablar y que explica que la figura del fantasma ${ }^{5}$ esté presente en gran parte de la poesía mistraliana.

El poco flujo que hay entre clases explica el insulto de 'aparecida'. Óscar Contardo comenta en su libro Siútico la condición de sociedad de súbditos más que de pares que se vive en Chile. El autor analiza la frase de un empresario que solicitado a explicar el auge de la economía chilena del siglo XXI indicó que su causa era "el aceptar el lugar que a cada uno le ha tocado, sin

5 Adriana Valdés ha interpretado el tema del fantasma en Tala como "el exilio del país que sea; la ausencia transformada a la vez en un país" (Valdés 93). Yo agregaría que el exilio mistraliano no es tan solo partida del país, sino expulsión del campo literario nacional y, en algunos poemas, imposibilidad de habitar en el mismo territorio. 
resentimiento, genera un clima social muy sano" (Contardo 155). Contardo interpreta este "aceptar el lugar que a cada uno le ha tocado" como una valoración exacerbada de la obediencia, por lo cual: "Más que la racionalidad para lograr el respeto de la comunidad lo importante es la sumisión a la jerarquía" (Contardo 156). Mistral se aleja de esta corte de súbditos y por ello le es dado el mote de 'aparecida', pero este insulto no resulta suficiente y se suma otro, el descalificativo de 'trascordada': "ahora las gentes dicen/ que eres cosa trascordada" (109). Grínor Rojo ${ }^{6}$ nos hace ver que "trascordada rima con renegada en "Montañas mías", y en otros contextos lo hará con descastada, trocada y desatentada, todo ello dentro del mismo campo semántico de no pertenencia, de extrañeza y confusión" (Rojo 312). El crítico identifica en 'trascordada' el insulto de 'renegada' que recibe Mistral, interpretación que comparto y a la cual agrego lo que Mistral hace con esta ofensa. La poeta da vuelta este insulto de 'trascordada', estableciendo para él otra circulación simbólica, donde ella se denomina positivamente "hija trascordada" (37). Leo este uso de "trascordada" como un gentilicio de los valles transversales al que se suma el significado de "estar atravesado", vale decir, la voz no termina el duelo con Chile. Cordón es también vínculo umbilical, estar comunicado con ese sitio que es Chile, "en montañas me crié/ (...) parece que nunca, nunca / aunque me escuche la marcha, / las perdí, ni cuando es de día/ ni cuando es noche estrellada" (37). Mistral reivindica la ruralidad como escena anterior, donde se vive el vínculo madre-hija, se mantiene el cordón umbilical, lo que a su vez la instala en el espacio tras-cordura, es decir más allá de las lógicas instituidas que situán la modernidad en la ciudad y oscurecen de la escena primigenia chilena del campo.

Mistral responde al mote de 'renegada', que significa la "que ha abandonado voluntariamente su religión y sus creencias" (RAE), con la elección de lo que considera lo propio, vale decir, su acompañante, el indígena norteño

6 En este texto me he tenido que suscribir a una cantidad limitada de críticas sobre la obra mistraliana, privilegiando aquellos que analizan Poema de Chile. No obstante me gustaría señalar algunos críticos sobre Mistral, entre los cuales cabe destacar a Soledad Bianchi, Ana María Cuneo, María Eugenia Góngora, Bernardita Llanos, Patricio Marchant, Leonidas Morales, Kemy Oyarzún, Pablo Oyarzún, Alicia Salomoné y Luis Vargas Saavedra, entre otros.

7 Susana Munich señala que "el carácter de trascordada le viene de que ya no recuerda cómo era su tierra y las costumbres de sus gentes. Es verdad que cuando desciende se acuerda, pero ese reconocimiento es el de una extranjera, que mira todo como si ya no fuera de aquí" (139). Munich acerca, tal como Rojo, 'trascordada' a renegada. 
cuyo nombre circula entre "huemulillo" (16) y "Niño-Ciervo" (17). Llama la atención la elección del ciervo como compañero de ruta, lo que me parece está por un lado vinculado a una imagen mitológica de despedazamiento, y por otro lado remite, por homofonía, al significante siervo-esclavo. Mitológicamente, el ciervo es el animal que recibe como castigo, en la tradición griega, la dispersión de sus miembros y la insepultura de los mismos ${ }^{8}$, y por tanto, metáfora del indígena ${ }^{9}$, en tanto cuerpo que el poema mistraliano busca reunificar y liberar de su condición subalterna. Los referentes "huemulillo"y "Niño- Ciervo" señalan la condición de subalternidad: huemul y no cóndor, niño y no adulto, siervo y no amo, indígena y no blanco. Esas son las identidades no hegemónicas que Mistral busca reinstalar para constituir el cierre y que revelan el objetivo de su viaje: "Te voy llevando a un lugar / donde al mirarte la cara / no te digan como nombre / lo de 'indio pata rajada', / sino que te den parcela / muy medida y muy contada" (140). El nuevo pacto social de Mistral propone una reubicación para el indígena, donde este tenga tierra y por ende no sea un 'pata rajada', vale decir, un herido de tanto caminar.

Niño, cervato y fantasma, estos personajes son efectos de discursos modernizadores: el indígena como animal, el indígena como niño y la mujer como naturaleza. Los tres efectos posibilitan el borramiento del sujeto, indígena o mujer, y lo transforman en cuerpos fantasmáticos. De esta forma, los tres caminantes son representaciones de cuerpos personales y sociales borrados que deben ser restituidos ${ }^{10}$. El aspecto de diatriba del poemario se vincula, en parte, con esta deuda por saldar, por ello, el niño-Ciervo le dice a Mistral que parece que porfiara contra otros: “Oye, por qué a veces, vos / calláis, mi mama - fantasma, / y parece ..., sí, parece/ que contra alguno porfiaras./ Yo no veo a nadie, pero/ es como que a alguien hablaras" (110). Efectivamente, ella pelea contra un discurso que le ha dado al indígena la condición y el

8 Este castigo se debía a la mirada inoportuna del ciervo sobre la diosa Diana desnuda (Durand 94).

9 Teresa Gisbert explica que la representación indígena de la muerte de Atahualpa, como un cuerpo separado en partes, tronco de miembros, no se condice con la realidad, muerte por garrote (ahorcamiento mecánico) que padeció; lo cual tiene que ver con la creencia indígena que el cuerpo desmenbrado en cuatro partes retonará unido, provocando la unión de los cuatro suyos del Imperio Incáico.

10 Santiago Daydí-Tolson propone una lectura de contrato autobiográfico: "Las figuras del niño indio y del huemul encarnan en un plano muy personal de representaciones emotivas, y en particular simbólica, a Yin Yin muerto" (193). 
mote de "pata rajada". Esta pelea es sinecdótica en el sentido de que apela a la necesidad de retornar el nombre a todas las etnicidades menos valoradas dentro del imaginario nacional, como los mapuches: "Hasta su nombre les falta. / Los mientan 'araucanos'/(...) Ellos fueron despojados,/pero son la Vieja Patria,/el primer vagido nuestro/nuestra primera palabra" (151). Aquí vamos al origen de la falta de nombre que se ubica en la catástrofe de la conquista, nos arrebataron las palabras ${ }^{11} \mathrm{y}$ con ello nos dejaron un efecto, el orden simbólico es para nosotros una impostura. El problema es relevado por Mistral en "Selva austral”: “-¿y qué dice eso 'Llanquihue'?/- ¡Ay! para nosotros, nada! / Porque fue la vieja gente/ la que, como Dios, mentaba, / y nombrar es un gran arte. / Tú y yo no sabemos nada." (169). Dado que "no hay identidad por fuera de la representación" (Arfuch 22), todos los chilenos que somos producto de la sustracción del lenguaje indígena, somos fantasmas.

La condición de sujetos espectrales me recuerda los versos de César Vallejo: "Qué extraña manera de estarse muertos. Quienquiera diría no lo estáis. Pero en verdad, estáis muertos" (117). En tanto, sujetos que somos originados en una sustracción de nuestra cultura ancestral, somos espectros. La condición de fantasma es la de aquella cosa que nos mira no verla. En el poema "Araucanos", Mistral problematiza el tema de lo indígena como lo invisibilizado por nosotros mismos: "Vamos pasando, pasando/ la vieja Araucanía / que ni vemos ni mentanos. / Vamos, sin saber, pasando/ reino de unos olvidados, / que por mestizos banales, / por fábula los contamos/ aunque nuestras caras suelen/ sin palabras declararlos" (150). Digo problematiza, porque en Mistral aquello invisibilizado no es solo la cosa externa, sino una parte de nosotros mismos que nos mira no verla. Mistral discute la intención de borrarnos lo moreno del rostro: "Quiere la gana de algunas / que en mi conflicto de garzas / yo me olvide de la gris / y me quede con la blanca, / pero tengo tentación / de quedar con la agrisada. / (...)/Vendrá mi hastío del blanco/ (...)/ Pero la blanca se tiene / tanta leyenda dorada / tanto le han cantado que / la van volviendo sagrada. / Y ya me cansa de fría, / de perfecta de alabada" (117). Mistral está aburrida de una nación que se empeña en llamarse blanca, como explica también Jorge Larraín: "desde muy temprano ha habido en Chile una valorización exagerada de la 'blancura' y una

11 El tipo de lenguaje usado por Mistral es examinado en la prosa por Olga Grandón quien afirma la cercanía de la poeta con el habla rural. 
visión negativa de los indios, (que ha incidido en que) mientras más oscura es la piel, más baja es la clase social" (232). La nación blanca nos vuelve a todos habitantes de Comala, nos quita cuerpo y nombre.

La mayoría de los insultos que Mistral reproduce en Poema de Chile están enunciados con la retórica del rumor. El denuesto de 'mujer pagana' que su acompañante le menciona adquiere esta forma del 'se dice que' u 'otros dicen': “-Que tú eres mujer pagana, / que haces unos locos versos / donde no mientas, dijeron, / sino a la mar y a los cerros" (154). El paganismo de la poeta sería su vínculo con la naturaleza. Mistral se presenta como la hija de la naturaleza y yo diría también 'hija natural', en tanto Godoy es borrado y sustituido por el viento. El recurso de Mistral con respecto a los insultos es enfatizarlos, si es calificada de pagana, ella se identifica con las hojas de boldo, porque: "Mienten sus hojas por rudas/ que no son cosa cristiana / pero vuelan por el mundo / sus hojas hospitalarias. / Corta, ponlas en tu pecho / aunque son duras son santas" (125). La tautología es que Mistral se representa metafóricamente en las hojas del boldo que vuelan por el mundo, a la vez que se señala como cristiana; un conflicto irresoluto que se inicia con el sincretismo colonial. Me detengo en este principio de identificación con la naturaleza ${ }^{12}$ porque veo allí la escena reprimida, por ejemplo, la denominación referida como mama ${ }^{13}$ puedo leerla como una metonimia de Pachamama ${ }^{14}$. El tema no es exclusivo de Poema de Chile, está presente en importantes textos anteriores, como "La otra" de Lagar, a partir del cual Raquel Olea explica que Mistral establece "una relación primaria con la naturaleza, anterior a cualquier dominio" (Olea 63). Me parece que Mistral, al establecer este tipo de cercanía con la naturaleza, recupera "la casta y el nombre" $(24)^{15}$ que fueron reprimidos tras la adopción española de Godoy. 'Mistral' es un

12 Una interesante reflexión sobre los devenires naturaleza en Mistral, analizados desde un punto de vista deleziano se encuentra en el artículo de Vilma Muñoz.

13 Soledad Falabella observa esta denominación 'mama' como una figura de plenitud buscada a la manera de utopía por la hablante. Concuerdo en la lectura y agrego el concepto de Pachamama para leer esa utopía.

14 Pachamama es un núcleo "simbólico de tradición andina (que alude) a la madre universal que alimenta toda la vida del mundo, como la diosa femenina de la tierra y la fertilidad, una divinidad agrícola benigna" (Montecino, Mitos 342).

15 Cito parte del poema "Noche de metales" donde se alude a cómo los orígenes fueron arrancados desde lo eterno a la manera de un mineral y cubiertos con 'amianto' que es similar a la cal. 
nombre más genuino en tanto vuelve al significante naturaleza a través del nombre de un tipo de viento.

El espectro concurre para pedir que se restituya lo desarreglado. Por ello, la poeta traza un mapa donde va evidenciando cómo en cada lugar ocurre el desmembramiento personal y social. La ciudad y sus cercanías están representadas como lugares nocivos para estos caminantes, tal como se aprecia en ciertos versos de "Jardines": "Mama, tienes la porfía / de esquivar todas las casas / y de entrarte por las huertas / a hurgar como una hortelana" (69), huida que la voz explica en razón de la forma de vida urbana y su contraste con la cultura campesina: "y todos por estos pastos / vivimos como hermanados, / y las santiaguinas solo / me ven escandalizadas / y gritan - ‘¡Válgame Dios!' / o me echan perros de caza" (69). Asimismo, en las viñas de la zona cercana a Valparaíso, observa el efecto del vino sobre la población: “entrando por los viñedos/que el Diablo trenza y destrenza/ (...) dan al animal y al indio/tufos de alcohol /al otro quemó el pastal/ que blanqueaba de corderos/y a mí me manchó, de niña/la bocanada del viento" (61). El alcohol es visto como una práctica disolvente del lazo social, lo que revela que no se presenta a Chile a través de una visión paradisíaca, sino que se le observa como un territorio en conflicto, donde todos participamos de la desconyunción de los miembros. El cuerpo despedazado se personifica también en la propia sujeto lírica, puesto que la asociación de la palabra 'viento' con 'mancha' remite al carácter furioso y violador que Mistral le asigna al fenómeno natural; por ende, ser hija del viento equivale a situar la marca de identidad en una violación que la rompe como unidad, la deja rota.

El sujeto lírico de Poema de Chile se identifica con el viento, estructura envolvente y disolvente, pero sin suelo. La carencia de Mistral se prolonga además por situarse fuera de los modelos de género: "no hacía lo de mis años:/no cosía, no zurcía, /tenía los ojos vagos, /cuentos pedía, romances, / y no lavaba los platos" (38). Quizás por ello, el castigo sobre la hablante proviene justamente de sus compañeras de género, de ahí que Mistral feminice la maldad: "Porque algunas cosas son/a la vez buenas y malas, /tal como ocurre con hojas/de un lado aterciopeladas/y con el otro te dejan/con la palma ensangrentada. /Casi no parecen hojas, /parecen mujeres malas" (132). En palabras de Eliana Ortega, "el patriarcado ha logrado separarnos a las mujeres" (www.gabrielamistral. uchile.cl). La mujer mala y la mujer aterciopelada constituyen una equivalencia, donde el género femenino se lee en la tela y su doblez. La poeta emplea el tópico de las rosas, no como alusión clásica a la fragilidad y belleza femenina, el sentido privilegiado por 
el soneto amoroso o la oda, sino como una polémica abierta con las prácticas de ese tipo de feminidad que la poeta contrasta con las características de la hierba, metáfora de la feminidad de la 'campesina rasa', valorando esta última: "Las flores de Chile son/tantas, tantas, mi chiquillo,/(...)/Unas serán las 'catrinas'16/ otras, campesinas rasas// Que ellas huelen todo el año/y las rosas una semana,/y tanto que pavonean/de su garbo y de su gracia.//Cuando ya te llegue el tiempo/de noviazgos y jaranas, /andarás también buscándolas/con la codicia en la cara" (77). Mistral le enseña al indígena que las 'rosas', las que exhiben su garbo no merecen elegirse como objetos de deseo y, por el contrario, lo invita a considerar a las campesinas que no utilizan la tela o el doblez.

Poema de Chile ha sido leído como "un recorrer geográficamente el territorio patrio" (Quezada 9). Es eso, pero debemos aceptar que es un viaje donde la protagonista evita la mayoría de las grandes ciudades y, por el contrario, destaca principalmente los poblados más pequeños y rurales. Además, el poemario va más allá de la descripción toponímica. En cada lugar geográfico, Mistral realiza un ejercicio seleccionador, ya que indica lo que debe ser incorporado en el proyecto nacional y lo que debe desecharse. Por ello, el poemario tiene un aspecto pedagógico que fue leído por Iván Carrasco: "el sentido etimológico de la palabra 'pedagogía' (paidos = niño; agog =conducir), se corresponde con precisión con la acción que realiza la mujer muerta en su postura de madre y maestra: guiar al niño indígena para que conozca su tierra y aprenda a vivir. El poema es, en esta perspectiva, una clase integrada de geografía, ciencias naturales, (...) la otra enseñanza, implícita, es religiosa, ecologista, feminista, intercultural, social, y forma un todo con la anterior" (Carrasco 122). Carrasco cita a Patricia Pinto e infiero que comparte su lectura: "Patricia Pinto (define) Poema de Chile como un espacio textual en una de cuyas zonas se instala el matriarcado. Invasión del espacio por lo femenino, expulsión física del varón" (Carrasco 118). Me sumo a la lectura de Pinto, a la vez que recalco lo siguiente, se trata del matriarcado de un mujer que vaga con un niño, a la manera de una madre soltera, y donde la enseñanza feminista consiste en situar y cercar los malos procedimientos de las mujeres: el cotilleo, la preocupación por los afeites

16 Catrín, na: Elegante, bien vestido, engalanado, emperelijado (Diccionario de la lengua española RAE). 
y el ninguneo, en otras palabras, Mistral denuncia la lucha de las mujeres contra las otras representantes de su género.

Michel de Certau, en su análisis sobre el problema del seudónimo, observa que "la denominación nueva se da como programa de ser" (129) y revela la descomposición del cuerpo simbólico que otorgaba el antiguo nombre. Siguiendo a de Certau, puedo leer la autodenominación de Mistral como un programa de defensa contra las mujeres-rosa-terciopelo, pues el apellido que se otorga es el nombre de un viento, lo inabarcable, "me lo hallé en tierras extrañas, /duro, juguetón, violento. /Las mujeres lo temían/como demonio de cuento; /a mí me doblaba el alma, /el respiro y el contento" (153). El viento se relaciona con la cólera cósmica y a la vez con el impetú creador (cfr. Bachelar). La designación del nombre 'Mistral' está asociada, en el poemario, a la tarea de desmoronar un orden simbólico cuyas columnas son, curiosamente, las mujeres llamadas 'las comadres': “-¡Cómo te echan a perder / las comadres cuando te hablan!" (109). De ahí que la violencia, la pena y la locura sean aspectos que caracterizan la nueva autodenominación: "El viento Norte viene / levantándose, ladino, / (...) / ¿sabe a qué baja el Loco? / Baja a cumplir su destino./ (...) Porque, sábelo, nosotros, poetas de él aprendimos /el grito rasgado, el llanto. “(33-34). Comparto con Santiago Daydí-Tolson, la lectura sobre la calificación de la locura como "excentricidad de lo libre y absoluto que no cabe dentro de las cláusulas de lo convencional" (219), a partir de lo cual veo la elección de Mistral, en tanto nombre, como subversión y protección contra su género. Este viento, tal como el fantasma, baja, para cumplir su función de alterar e impartir justicia frente a las fechorías cometidas por las mujeres cotilleras y a los crímenes con despedazamiento sufridos por los indígenas.

El programa de Mistral es evidenciar que hay un tiempo que transcurre bajo el sintagma del crecimiento moderno que despedaza y borra, fabricando un orden violento que relega lo no urbano al margen de lo invisible. La inscripción de sí misma como Mistral le confiere la potestad de actuar frente a ese desajuste. Su poder es pneumático y reparador, pero estas funciones no son inocuas, implican un rechazo a los modos de tutelaje que funcionan en la sociedad chilena, y potenciar la idea del viento como entidad sin procedencia precisa. El viento aparece sin carta de recomendación. Mistral es la 'aparecida'. Desde este punto de vista, su rechazo a las ciudades es la doble faz de una protesta contra la sociedad cortesana. La voz recopila en ese lugar todo lo amenazante y ante él, prefiere declararse hija de la naturaleza, trazando su vínculo de origen hacia el viento que la rompe y la crea como 
poeta. Tal como señala Derrida, los fantasmas son "nuestros remordimientos, los títulos de nuestra gloria" (Derrida 19). En este caso, el espectro se relaciona con la culpa producida por el asesinato de nosotros mismos y el cual, a veces, mostramos con orgullo. Por eso, el espectro que recorre Chile es el cuerpo que la cultura chilena borró, despedazó, en su mirada etnocéntrica y patriarcal, pero que ahora regresa bajo la posibilidad de reunirse, nombrarse y saldar la deuda.

\section{BIBLIOGRAFÍA}

Arfuch, Leonor. Identidades, sujetos y subjetividades. Buenos Aires: Prometeo, 2002.

Bachelar, Gastón. El aire y los sueños: Ensayo sobre la imaginación del movimiento. Trad. Ernestina de Champourcin. México: FCE, 1958.

Carrasco, Iván. "Poema de Chile: Un texto pedagógico". Revista Chilena de Literatura 56 (2000): 117-127.

Certau, Michel de. Historia y psicoanálisis. Trad. Alfonso Mendiola. México: Universidad Iberoaméricana, 2003.

Contardo, Óscar. Siútico: Arribismo, abajismo y vida social en Chile. Santiago: Vergara, 2008.

Daydí-Tolson, Santiago. El último viaje de Grabriela Mistral. Santiago: Aconcagua, 1989.

Derrida, Jacques. Espectros de Marx: El estado de la deuda, el trabajo del duelo y la nueva Internacional. Trad. José Miguel Alarcón. Madrid: Editora Nacional, 2002.

Durand, Gilbert. Las estructuras antropológicas de lo imaginario. Madrid: Taurus, 1981.

Falabella, Soledad. ¿Qué será de Chile en el cielo? Poema de Chile de Gabriela Mistral. Santiago: Lom, 2003.

Gisbert, Teresa. Iconografia y mitos indigenas en el arte. La Paz: Gisbert y Cía. 1980.

Grandón, Olga. "El acervo rural en los Recados en prosa de Gabriela Mistral”. Revista electrónica Cyber Humanitatis 23, invierno 2002.

Lacan, Jacques. "El seminario sobre la carta robada", "Función y campo de la palabra". Escritos I. Trad. Tomás Segovia. Madrid: Siglo XXI, 1984: 5-35, 227-310.

Larraín, Jorge. Identidad chilena. Santiago: Lom, 2004.

Mistral, Gabriela. Poema de Chile. 1967. Edición y prólogo a cargo de Jaime Quezada. Santiago: Seix Barral, 1985.

Marchese, Angelo y Joaquín Foradellas. Diccionario de retórica, crítica y terminología literaria. Barcelona: Ariel, 1989.

Mercurio. "Gente como uno: Discriminación y clasismo en Chile". El Mercurio. Santiago, 22 de agosto, 2004: E1-E3.

Montecino, Sonia. Madres y Huachos: Alegorías del mestizaje chileno. Santiago: Editorial Sudamericana, 2001. 
Mitos de Chile: Diccionario de seres, magias y encantos. Santiago: Editorial Sudamericana, 2003.

Münnich, Susana. Gabriela Mistral: Soberbiamente transgresora. Santiago: Lom, 2005.

Muñoz, Vilma. "La escritura de 'Valle de Elqui', de Poema de Chile: Pliegue recuerdo-naturaleza". Acta literaria 33 (2006): 55-70

Olea, Raquel. "Otra lectura de 'La Otra'”. Acta literaria 14 (1989): 59-57.

Ortega, Eliana. “Amada amante: Discurso feminil de Gabriela Mistral”. Una palabra cómplice: Encuentro con Gabriela Mistral. Editoras Raquel Olea y Soledad Falabella. Santiago: Cuarto Propio, 1990. También en www.gabrielamistral.uchile.cl

Paredes, Pablo. El final de la fiesta. Santiago: Calabaza del diablo, 2005.

Pinto, Patricia. "La mujer en Poema de Chile: Entre el decir y el hacer de Gabriela". Acta literaria 14 (1989): 25-43.

Pizarro, Ana. Gabriela Mistral: El proyecto de Lucila. Santiago: Lom, 2005.

Romero, José Luis. Latinoamérica, las ciudades y las ideas. Argentina: Siglo XXI, 2001.

Rojo, Grínor. Dirán que está en la gloria. Santiago: FCE, 1997.

Subercaseaux, Benjamín. Chile o una loca geografia. 1940. Santiago: Ercilla, 1954.

Thiebaut, Carlos. Historia del nombrar. Madrid: Visor, 1990.

Valdés, Adriana. "Identidades tránsfugas". Una palabra cómplice: Encuentro con Gabriela Mistral. Editoras Raquel Olea y Soledad Falabella. Santiago: Cuarto Propio, 1990. 8597.

Vallejo, César. Trilce. 1922. Buenos Aires: Losada, 1979. 